\author{
Milan NIKOLIC* \\ Katarina ZORIC* \\ Edit TEREK* \\ Dragana GLUSAC* \\ Dragan COCKALO*
}

\title{
Research into the evaluation of PR activities in companies from Serbia
}

\begin{abstract}
This paper presents the results of a research into the volume, type and quality of the evaluation of public relations activities in companies in Serbia. The survey was conducted via a web survey. The responses were collected from 50 PR service managers from 50 companies in Serbia. The results are presented through descriptive statistics and correlation analysis where some of the observed sizes of the connection were analyzed. The main conclusions can be summarized as follows: PR functions are often not assigned sufficient importance in companies in Serbia; the evaluation of PR activity is slightly neglected compared to other PR activities; intensive and continuous evaluation of the performances of PR activities increases the likelihood of the complete PR function of the company being successful; companies that are not so successful use evaluation less than successful companies; the evaluation of PR activities is mostly done through a method for measuring quantity; the main problems in the evaluation of PR activities are lack of time and money. The evaluation of PR activities in companies in Serbia can be improved through a greater understanding on the part of top managers, and also by hiring additional PR practitioners.
\end{abstract}

Keywords: Public Relations, evaluation of PR activities, the success of PR function, Serbia.

\section{Introduction}

Public Relations can be defined as a strategic communication process that aims to create, maintain and promote mutually beneficial cooperation between the organization and its environment (PRSA, 2012). According to Kotler and Armstrong (1996), public relations professionals' aim is to build good relationships with different audiences, to build a good image of the organization and resolve problems due to unfavorable stories, rumors and events. Public relations are a business activity that is focused on establishing, maintaining and developing an understanding of the different segments of the public. It is the organization's communication activity aimed at ensuring public confidence and creating a positive and favorable image of the organization in public. According to Cutlip, Center and Broom (2006), public relations are a management function that identifies, establishes and maintains mutually beneficial relationships between the organization and the public, on which the success or failure of an organization depends.

Each organization manages various forms of communication with the environment. So, in every company, there are public relations, regardless of whether a formal function bears this name. Moreover, there is almost no communication without the elements of PR. The ma-

* Dept. of Management, University of Novi Sad, Technical Faculty "Mihajlo Pupin”, Zrenjanin, Serbia; Corresponding author: Edit Terek, terekedita@gmail.com. 
jority of commercial, political or personal failures can be explained by poor communication with the environment. The success of an organization depends significantly on its ability to manage communication and information exchange. Today, there is a significant interest in the state and development of the PR profession and PR practice around the world.

Public Relations shows that influencing public opinion can result in achieving various goals from raising awareness about an issue, to persuading people to certain actions. PR practitioners must be able to identify public opinion, and to be able to react, strengthen or change it. Every persuasive and influential process is carried out according to the scheme: broadcasting messages - attitude forming or changing - change in behavior (Gordon, 2011).

There are a significant number of public relations activities. These activities can be classified and maintained in several ways. According to Wilcox and Cameron (2009), public relations activities are systematized as follows: media relations (press releases, press conferences, publicity), publications (internal and external), sponsorship, lobbying, organizing special events (Press conferences, symposiums, exhibitions and performances, openings and cocktail parties, organizing meetings), corporate image and corporate identity, internal public relations and public relations in crisis. Sometimes it is difficult to determine how all these PR activities affect the success of the organization, its image, brand, sale of products and other indicators of success. To overcome this problem, it is necessary to perform the regular and continuous evaluation of public relations. The very concept of evaluation means assessment.

Evaluation provides PR practitioners with information on the success of the undertaken activities and achieved effects. Evaluation assesses whether the set communication objectives have been achieved. However, evaluation is not only a process of evaluating the success of certain practices. It also provides an opportunity for development and improvement in certain processes and activities, such as giving guidance for PR practitioners in further work (Wilcox \& Cameron, 2009). The importance of evaluation is also emphasized in the presentation of the accountability and effectiveness of PR campaigns (Dozier, 1990; Fairchild, 2002, White \& Blamphin, 1994), as well as in the presentation of the impact of public relations on the success of an organization (Radford \& Goldstein, 2002). Thus, in the field of public relations, the evaluation of PR activities is a very important and indispensable procedure for the development of a company's PR functions, as well as for the success of the organization as a whole.

Many public relations companies and institutes, along with a number of researchers, scientists and PR practitioners have discussed the need to develop evaluation techniques, to determine the measurement structures as well as the role and importance of measurement. However, there are still no clear answers to these questions and problems. An additional difficulty has emerged because of the constant development of communication technology. Modern communication is carried out without interruption, so further pressure is placed on PR practitioners to constantly monitor "influential communication" trends which they in turn and they have to "influence" continuously.

For many years the measurement and evaluation of the effectiveness of public relations has been one of the major problems faced by PR practitioners and researchers (Watson, 2012). However, there is still a lack of more sophisticated methods for the measurement and evaluation of public relations despite an increasing need for their application (Baskin et al., 2010). While PR professionals use a number of techniques for measuring and evaluating the effectiveness of public relations, it is still unclear to what extent the results of such evaluation matches real outcomes (Xavier et al, 2005). According to Sha (2011), the PR profession has 
changed significantly over time, but PR practice itself has remained the same. Therefore, the issue of evaluation in public relations has existed for many years and is still very relevant. At the same time, there are a significant number of papers on how the evaluation of public relations really affects the overall effectiveness of the PR function and the overall effectiveness of a company.

A significant number of PR professionals in Serbia have been recorded only since the year 2000 (Nikolic, Dorðevic, \& Cockalo, 2007). Results of a recent survey show that progress was made, between 2006 and 2012, in the development of the PR profession in Serbia (Nikolic et al., 2012). Unfortunately, despite the noticeable improvement in the overall development of public relations in Serbia, one cannot expect trends in the field of the evaluation of PR activities to be monitored to the same degree as at the global level. The research in this paper is directed towards testing the condition, significance and interrelations of the components of the evaluation of public relations in companies in Serbia. The research results should form the basis for the diagnosis of the condition and importance of evaluating PR activities, understanding the impact evaluation of PR activities and the loss of PR function and the enterprise as a whole, as well as developing awareness among managers about the importance of evaluating PR activities.

\section{Public relations in Serbia}

In theory, public relations have been present in Serbia since the mid eighties of the twentieth century. A more significant study of public relations began in the early nineties that followed. During this period the practical application of public relations in Serbian companies began. At the same time, at the beginning of the nineties, the College of Economics and the College of Organizational Sciences in Belgrade began offering a major in public relations at the master studies level. In parallel with the study of public relations at Master's degree level at the aforementioned faculties, the study of public relations in the field of non-formal education began, and very good results were achieved. In the mid nineties, several public relations agencies appeared in Serbia.

In a number of Serbian companies, public relations were an unrecognised area in the nineties. In this initial period, public relations played a minor role in the overall process of communication for Serbian companies, in terms of performance in both the domestic and international markets. In the late nineties of the last century, with the emergence of a number of international advertising agencies, public relations came to feature as a significant presence within Serbian companies. The development of the market economy, and acceptance of the logic of private capital, has contributed to a greater understanding among people of the role and importance of public relations, and therefore to its acceptance as a serious and important profession. It can be said that the intensive development of public relations in Serbia began after the year 2000. Since then, and especially in the last few years, PR practice has made significant advances, especially thanks to the entrance of an increasing number of foreign companies into the Serbian market. Previous research (Nikolic et al., 2012) indicates that significant progress is in evidence, and points to better prospects for the PR profession, as well as a better understanding and greater respect for PR practitioners in Serbia.

Most PR practitioners in Serbia attended the appropriate informal seminars and courses. The speakers at these seminars were mainly experts in the various fields related to public re- 
lations: journalism, communication, marketing, management, etc. According to previous education, PR practitioners in Serbia are mainly economists, managers, journalists or professors of Serbian language and literature, but there are other professions too (Nikolic, Dorðevic \& Cockalo, 2007).

When it comes to public relations in Serbia, it is important to note an association of professionals: the Public Relations Society of Serbia (Serbian Association of Public Relations DSOJ). The Serbian Association for Public Relations (DSOJ) was established on May 17th, 2004. The DSOJ continues the tradition of the PR Society of Yugoslavia - the oldest professional organization in this field from the former Yugoslavia. The DSOJ was founded by prominent representatives from Universities, public relations agencies, government institutions and organizations, as well as large private companies. The organisation has over 200 members from all segments of society (PR agencies, businesses, government agencies, universities, NGOs as so on), and their number increases monthly as they gain on average 10 new members. 24 PR agencies in Serbia have members in the DSOJ (www.pr.org.rs).

The mission of the Association is to contribute to the improvement of the field and profession of public relations, through implementing and applying the highest professional and ethical standards, putting into effect high-quality professional programmes, conferences and seminars, as well as facilitating international cooperation and the exchange of experiences. Long-term goals that the DSOJ stands for, in addition to the objectives set in their mission, include improving education and training among the general and professional public. In cooperation with businesses, organisations and professionals in fields that are related, as well as others, the DSOJ contributes to the improvement of public relations at all levels in the country (www.pr.org.rs).

The activity of the DSOJ is public, and access to membership is available to all citizens of the Republic of Serbia who are professionally engaged in activities and public relations, and who meet certain criteria (more information can be found at the DSOJ's website, www.pr.org.rs).

\section{Theoretical background and assumptions}

\subsection{The development of the need to evaluate PR activities}

Over time the need to develop measures and methods for the evaluation of communication can be monitored. By analyzing different studies a slow but continuous growth in the need for this PR activity can be seen. According to Gruning (1983), enthusiasm for the need for evaluation existed among practitioners; however, the gap between the need and actual practice was significant. One of the reasons for the existence of this gap was a distinct fear among PR practitioners of being able to measure their success. More than half of the respondents admitted experiencing this fear (Kirban, 1983). Furthermore, Grunig and Hunt (1984) showed that most practitioners are led by intuition rather than scientific procedures in solving various PR problems. This state of the public relations profession gave rise to the feeling that this was an "immature and non-effective science" (Pavlik, 1987). Other research work (Lindenmann, 1990) revealed that most PR measurements do not have a "scientific" character, however, $53 \%$ of the respondents expressed the hope that in the next ten years there will be a 
change in this regard. Nine out of ten respondents agree that PR research needs to become more sophisticated.

At the beginning of the 1990s there was a noticeable improvement in the acceptance of the need for evaluation (IPRA, 1994; Walker, 1997). The evaluation of public relations is perceived as one of the most important issues and research priorities in this field (Macnamara, 1996; White \& Blamphin, 1994). Watson (1992) found that $76 \%$ of the respondents use monitoring (not evaluation) press clippings and "intuitive and professional" assessment of the results of activities. Macnamara (1993) showed that only 13\% of PR practitioners and $9 \%$ of PR consultants focus on objectives when evaluating the success of a PR campaign. A study by the International Public Relations Association (IPRA, 1994), showed that the gap between the opinions of PR practitioners on the importance of evaluation and specific action taken with regard to the evaluation, still exists. While $75.9 \%$ of the PR practitioners in the U.S., $90 \%$ in Australia, $89.1 \%$ in South Africa and $89.8 \%$ of the IPRA members thought it necessary to evaluate PR practice, $16.0 \%, 14.0 \%, 25.4 \%$ and $18.6 \%$ of the PR practitioners (respectively) used evaluation in practice (IPRA, 1994).

More recent monitoring of the PR profession has shown some progress compared to the 1990s. The research studies carried out in 2001 and 2003 showed a significant increase in the use of different measures of evaluation, however, press clippings and the "intuitive assessment" of PR practitioners were still the most common (Macnamara, 2005). On the other hand, satisfaction with the level of evaluation by the PR staff and customers was extremely low in comparison with the satisfaction of the evaluation, for example, of marketing activities (Macnamara, 2005).

In June 2010, several world leading professional organizations in the field of public relations presented seven new principles for the measurement and evaluation of public relations, also known as The Barcelona Principles (Grupp, 2010):

1. Goal setting and measurement are fundamental aspects of any PR program.

2. Measurements related to the media must be quantitative and qualitative. Clipping by itself is not sufficient.

3 Advertising Equivalency (AVE) does not measure the value of public relations and does not provide information on future activities.

4. Measurements related to social media can and should be pursued.

5. Measurement of outcomes should be preferred compared to the measurement of out-takes.

6. Business results can and should be measured where possible.

7. Transparency and repeatability are of exceptional importance in measuring.

In 2011, the third European Summit on measurement was held in Lisbon. At this summit a list of the highest priority problems within the measurement and evaluation of communication was created, for which solutions should be found before the year 2020. The highest priority issues are presented in the following order (AMEC, 2011):

1. How to measure return on investment (ROI) within public relations.

2. Creating and acceptance of global standards for social media measurement.

3. Measurement of PR campaigns and programs should become part of internal PR activities.

4. Creating programs to raise awareness about the importance of the customer measurement outputs, outcomes and results of successful PR programs.

5. Defining approaches that would allow displaying the influence of corporate image creation and value increase. 
Other prominent issues within the measurement and evaluation of public relations included: measuring the impact of internal and external communication in order to achieve business objectives, acceptance and development of standards for measuring social change, developing new business language, the further impact on the rejection of the use of AVE in the PR evaluation, defining ways to measure the impact of PR on the formation of brand values. (AMEC, 2011).

When it comes to the Western Balkans, it is useful to mention two events. In October 2010, at the Croatian Association of Public Relations conference in Zagreb a book was presented, "Measurement and Evaluation in Public Relations", edited by Betteke van Ruler, Ana Tkalac Vercic and Dejan Vercic, which is a significant publication in the field of public relations. In 2012, the DSOJ (Serbian Association of Public Relations) organized lectures on the methods of measurement and evaluation of public relations, which have already been implemented in Serbia by some PR practitioners. Lectures were held in order to raise awareness about the importance of this topic among practitioners.

\subsection{Measurement and evaluation of public relations}

Evaluation is basically the process of assessing the quality and effectiveness of a process. Evaluation is a key element of communication strategy - campaign. Undertaken activities must be evaluated so their success can be measured. In this way learning from experience is achieved. According to Wilcox and Cameron (2009), the evaluation of public relations can be defined in the following range:

1. Evaluation is the systematic assessment of the program and its results. For a PR practitioner this means expressing responsibility to the client and to himself.

2. A PR program is designed to have a meaningful impact - changing or maintaining a particular opinion. Thus, after its implementation, it is necessary to apply certain research activities in order to measure and document the effects of PR programs.

3. Evaluation refers to methodically and regularly assessing progress in achieving the specific targets of PR programs. Based on this evaluation, we can learn what has been done well and what poorly, what progress has been made, and most importantly, how a similar PR program could be better implemented in the future.

Noble and Watson (1999) note that it is possible to single out the top five models for the research and evaluation of public relations: the PII Model (Cutlip, Center, \& Broom, 1985), the Macro Model of PR Evaluation, later renamed the Pyramid Model of PR Research (Macnamara, 1992, 1999), the PR Effectiveness Yardstick (Lindenmann, 1993), the Continuing Model Evaluation (Watson, 1997), and the Unified Model of Evaluation (Noble \& Watson, 1999). To this list one may add two other prominent models for the measurement and evaluation of public relations (Macnamara, 2005): the IPR PRE process (The UK Institute of Public Relations) and the Measurement Tree (The Institute of Public Relations USA).

Literature in the field mentiones three levels of measurement and evaluation in public relations (Lindenmann, 1993; Noble \& Watson, 1999; Wilcox \& Cameron, 2009). The first level involves a quantitative analysis of sent and appearing messages in the media (output), without further assessment. The second level is measured by the degree of the message reception, the level of awareness of the audience about the existence and purpose of the sent messages, as well as the level of understanding, acceptance and memorization of such messages (outtake). At the third level, the consequences are measured, i.e., everything that hap- 
pens when the target public, under the influence of PR programs, change opinions, attitudes and behavior (outcome).

According to the previous research (Watson \& Simmons, 2004), when evaluating, PR practitioners mostly make their evaluation at the output level. The data obtained in this analysis provides information on the performance of campaigns, or on the achieved coverage of messages. The results of this analysis, however, do not say anything about what it means for the company today, and what it will mean in the future, or what quality of communication was achieved. Media monitoring is the most common form of evaluation of public relations at this level.

Based on the above considerations, the following assumptions are set in this paper:

A1: PR activity evaluation is significantly neglected in companies in Serbia.

A2: The evaluation of PR activities in companies in Serbia mostly comes down to the method for measuring quantity.

A3: Lack of time and money are the main barriers for the evaluation of PR activities in companies in Serbia.

A4: PR activity evaluation has a statistically significant impact on the overall success of PR function.

A5: PR activity evaluation has a statistically significant impact on the overall success of a company.

\section{Research Method}

\subsection{Questionnaire}

The research into evaluating public relations activities in companies in Serbia was carried out through a web survey. This survey contains 11 questions, some of which include sub-questions (a total of 29 questions). All 29 questions provide an opportunity to reply with a score ranging from 1 to 5 , where 5 is always the best score. The questions are given in Table 1 .

The questions from the questionnaire were created following the example of several references and leading models of public relations evaluation. In addition, some questions were formulated to take into account the needs of research in Serbia. In addition, some questions were added because of the needs of this study.

In their study, Watson and Simmons (2004) asked the respondents to answer a question regarding how frequently they use evaluation methods in measuring the effectiveness of PR campaigns. The same question is used by the present study (question p1) to gather information about the frequency of using evaluation methods in companies.

Questions p2, p3 and p4 enable PR practitioners to evaluate the performance of the evaluated activities, the PR function, as well as the overall success of the company. These issues are important for testing the correlation with other issues, for example: question $\mathrm{p} 1$ (scope of application of evaluation) and p10 (problems in the evaluation).

Furthermore, Watson \& Simmons (2004) asked the respondents to answer a question regarding to what extent they use certain techniques for the evaluation of the undertaken PR activities. Similarly, the same question is used by the present study (question p5). The actions were specified by PR systematization which was used in the reference (Cameron \& Wilcox, 2009). 
Watson and Simmons (2004) also examined the evaluation methods used in the measurement of PR campaigns. In doing so, the evaluation methods were observed across the three levels of measurement and evaluation in public relations: methods for measuring the quantity (measurement of performance - output), methods for measuring the awareness of the audience (the measurement results - outtake), and methods for measuring the consequences (consequence measurement - outcome). Question p6 measures the frequency of using evaluation on the level of output, outtake and outcome in companies in Serbia. The questions p6 and $\mathrm{p} 7$ provide insight into the thoughts of PR practitioners on the effects of activities undertaken at various levels of measurement.

Other research work (Gruning, 1983; IPRA, 1994) suggests that there is a gap between PR practitioners' awareness of the importance of evaluating PR activity and actual practice. Questions p8 and p9 offer the possibility of comparing the state of consciousness between PR practitioners on the subject and the practice applied in Serbia.

In his study Macnamara (2005) found that there are three barriers to the evaluation of PR activities: lack of money, lack of time and lack of "need" for evaluation. Apparently, the main obstacle is the lack of money, time, knowledge and human resources (Watson \& Simmons, 2004). In accordance with previous research, a similar question is used by the present study (question $\mathrm{p} 10$ ). This question is related to the barriers that stand in the way of evaluating the performance of PR activities in companies in Serbia (lack of time, money, knowledge and awareness).

In developing the questionnaire the possibility that PR practitioners do not perform evaluation activities individually, but by using a specialized PR agency was taken into account. Question p11 provides insight into the frequency of using the services of external PR agencies in the evaluation of PR activities.

\subsection{Subjects and data collection}

Executives from PR companies and organizations in Serbia were selected as the respondents. The study included successful companies that have a PR service, that is, companies that are supposed to implement methods for evaluating their PR activities. The respondents were previously contacted, and were then sent an e-mail with a link to the on-line questionnaire.

The survey was conducted during the period between August and October 2013. 50 responses were collected from 50 PR service managers from 50 companies in Serbia. Successful PR executives may be accepted as experts in the field of practical applications of the evaluation of PR activities.

\section{Results}

\subsection{Descriptive statistics}

The descriptive statistics for the questions are shown in Table 1. The table gives the questions themselves, the abbreviations for each question, the mean value of the answers to the questions (the marks range from 1 to 5), standard deviation and Cronbach's alpha for each characteristic set of questions. 
Table 1. Descriptive statistics.

\begin{tabular}{|c|c|c|c|c|}
\hline Questions & Abbreviations & Mean & $\begin{array}{c}\text { Stand. } \\
\text { dev. }\end{array}$ & $\begin{array}{l}\text { Cronb. } \\
\text { alpha }\end{array}$ \\
\hline $\begin{array}{l}\text { 1. To what extent do you use the evaluation of PR } \\
\text { activities in your company? }\end{array}$ & $\mathrm{p} 1$ & 3.56 & 1.128 & \\
\hline $\begin{array}{l}\text { 2. How do you evaluate the effectiveness of the } \\
\text { evaluation of PR activities in your company? }\end{array}$ & p2 & 3.26 & .965 & \\
\hline $\begin{array}{l}\text { 3. How do you rate the overall effectiveness of PR } \\
\text { function in your company? }\end{array}$ & p3 & 3.78 & .708 & \\
\hline $\begin{array}{l}\text { 4. How do you evaluate the effectiveness of your } \\
\text { company as a whole? }\end{array}$ & p4 & 4.02 & .869 & \\
\hline $\begin{array}{l}\text { 5. To what extent do you use evaluation of individual PR } \\
\text { activities in your company? }\end{array}$ & p5 & & & \\
\hline Publications & p5.1 & 3.56 & 1.163 & .836 \\
\hline Sponsorship & p5.2 & 2.98 & 1.270 & \\
\hline Lobbying & p5.3 & 2.92 & 1.368 & \\
\hline Organization of special events & p5.4 & 3.78 & 1.183 & \\
\hline Corporate image and corporate identity & p5.5 & 3.78 & 1.166 & \\
\hline Internal relations & p5.6 & 3.66 & 1.081 & \\
\hline Crisis PR & p5.7 & 3.80 & 1.245 & \\
\hline Public relations on the international market & p5.8 & 2.84 & 1.419 & \\
\hline $\begin{array}{l}\text { 6. How often do you use the following methods for the } \\
\text { evaluation of PR activities in your company? }\end{array}$ & p6 & & & \\
\hline $\begin{array}{l}\text { Methods for measuring quantity } \\
\text { (Calculation of the number of messages in a given period } \\
\text { and the number of repetitions of certain messages). }\end{array}$ & p6.1 & 3.62 & 1.323 & .865 \\
\hline $\begin{array}{l}\text { Methods for measuring the awareness of the audience } \\
\text { (measure of awareness of the existence of messages, } \\
\text { measurement of message understanding and } \\
\text { measurement of message memorization). }\end{array}$ & p6.2 & 2.90 & 1.216 & \\
\hline $\begin{array}{l}\text { Methods for measuring the consequences } \\
\text { (measuring the changes in the opinions, attitudes and } \\
\text { behaviors of the audience). }\end{array}$ & p6.3 & 3.04 & 1.177 & \\
\hline
\end{tabular}




\begin{tabular}{|c|c|c|c|c|}
\hline $\begin{array}{l}\text { 7. To what extent do you believe that PR activities in your } \\
\text { company impact on...? }\end{array}$ & p7 & & & \\
\hline $\begin{array}{l}\text {... no. of posts in a period and number of repetitions of } \\
\text { certain messages? }\end{array}$ & p7.1 & 3.74 & .965 & .881 \\
\hline $\begin{array}{l}\text {...awareness of the audience about the existence of } \\
\text { messages, message understanding and message } \\
\text { memorization? }\end{array}$ & p7.2 & 3.58 & .906 & \\
\hline $\begin{array}{l}\text {...changes in opinions, attitudes and behaviors of the } \\
\text { audience? }\end{array}$ & p7.3 & 3.40 & 1.030 & \\
\hline $\begin{array}{l}\text { 8. How important do you believe the evaluation of PR } \\
\text { activities is ...? }\end{array}$ & p8 & & & \\
\hline $\begin{array}{l}\ldots \text { for the success of current PR activities (activities for } \\
\text { which evaluation is done)? }\end{array}$ & p8.1 & 4.10 & .814 & .848 \\
\hline ... for the success of future PR activities? & p8.2 & 4.32 & .653 & \\
\hline ... for the success of PR function in general? & p8.3 & 4.24 & .744 & \\
\hline $\begin{array}{l}\text { 9. To what extent do you use the results of the evaluation } \\
\text { of PR activities in your company ...? }\end{array}$ & p9 & & & \\
\hline $\begin{array}{l}\ldots \text { for the success of current PR activities (activities for } \\
\text { which evaluation is done)? }\end{array}$ & p9.1 & 3.50 & 1.015 & .930 \\
\hline ... for the success of future PR activities? & p9.2 & 3.64 & 1.083 & \\
\hline$\ldots$ for the success of PR function in general? & p9.3 & 3.58 & 1.090 & \\
\hline $\begin{array}{l}\text { 10. What are the barriers to evaluating PR activities in } \\
\text { your company? }\end{array}$ & p10 & & & \\
\hline Lack of time for the evaluation of PR activities. & p10.1 & 2.96 & 1.087 & .497 \\
\hline Lack of money for the evaluation of PR activities. & p10.2 & 3.06 & 1.114 & \\
\hline $\begin{array}{l}\text { Lack of knowledge in the field of the evaluation of PR } \\
\text { activities. }\end{array}$ & $\mathrm{p} 10.3$ & 2.26 & 1.121 & \\
\hline $\begin{array}{l}\text { Lack of awareness of the importance of evaluating PR } \\
\text { activities. }\end{array}$ & p10.4 & 2.30 & 1.111 & \\
\hline $\begin{array}{l}\text { 11. To what extent do you use the services of other } \\
\text { (external) PR agencies in the evaluation of PR activities in } \\
\text { your company? }\end{array}$ & p11 & 2.08 & 1.243 & \\
\hline Valid N (listwise) & 50 & & & \\
\hline
\end{tabular}

\subsection{Correlation analysis}

Table 2 shows the results of correlation analysis between individual questions. These results refer to the total sample of $\mathrm{N}=50$ subjects. Pearson correlation was used. In Table 2, a statistically significant correlation is indicated as follows: $* \mathrm{p}<0.05, * * \mathrm{p}<0.01$. 
Table 2. Correlation analysis.

\begin{tabular}{|l|l|l|l|l|l|l|l|l|l|l|l|}
\hline & $\mathrm{p} 1$ & $\mathrm{p} 2$ & $\mathrm{p} 3$ & $\mathrm{p} 4$ & $\mathrm{p} 6.1$ & $\mathrm{p} 6.2$ & $\mathrm{p} 6.3$ & $\mathrm{p} 10.1$ & $\mathrm{p} 10.2$ & $\mathrm{p} 10.3$ & $\mathrm{p} 10.4$ \\
\hline $\mathrm{p} 1$ & & & & & & & & & & & \\
\hline $\mathrm{p} 2$ & .201 & & & & & & & & & & \\
\hline $\mathrm{p} 3$ & $.541^{* *}$ & .115 & & & & & & & & & \\
\hline $\mathrm{p} 4$ & .238 & -.031 & $.339^{*}$ & & & & & & & & \\
\hline $\mathrm{p} 6.1$ & $.652^{* *}$ & $.303^{*}$ & $.453^{* *}$ & .273 & & & & & & & \\
\hline $\mathrm{p} 6.2$ & $.592^{* *}$ & .249 & $.353^{*}$ & .253 & $.686^{* *}$ & & & & & & \\
\hline $\mathrm{p} 6.3$ & $.536^{* *}$ & .116 & $.353^{*}$ & .219 & $.626^{* *}$ & $.744^{* *}$ & & & & & \\
\hline $\mathrm{p} 10.1$ & $-.281^{*}$ & -.262 & $-.303^{*}$ & -.215 & $-.422^{* *}$ & $-.404^{* *}$ & $-.413^{* *}$ & & & & \\
\hline $\mathrm{p} 10.2$ & -.271 & -.072 & $-.345^{*}$ & $-.444^{* *}$ & $-.386^{* *}$ & $-.387^{* *}$ & $-.360^{*}$ & $.373^{* *}$ & & & \\
\hline $\mathrm{p} 10.3$ & -.198 & -.271 & -.106 & -.257 & $-.510^{* *}$ & $-.414^{* *}$ & $-.487^{* *}$ & $.410^{* *}$ & $.396^{* *}$ & & \\
\hline $\mathrm{p} 10.4$ & -.055 & .002 & -.122 & -.218 & $-.296^{*}$ & -.083 & -.228 & .264 & $.348^{*}$ & $.509^{* *}$ & \\
\hline
\end{tabular}

\section{Discussion}

Table 1 shows the values [0][0] of Cronbach's alpha, which range in the interval from á $=0.497$ to á $=0.930$. Cronbach's alpha was calculated for typical sets of questions. Since we are not talking about classic dimensions, the value of Cronbach's alpha may have a lower value than those normally allowed. This is the case in the group of questions p10 (á $=0.497$ ). This slightly lower value indicates that there is a significant difference in the scores for those questions within group p10. For example, a company that has a problem with the time to evaluate the PR activities may not have problems with money for performing the same evaluation. Or another possible situation may be that the company has expressed an awareness of the importance of evaluating PR activity, but there is a lack of knowledge in this area.

The mean values $[0][0]$ for the first four questions show that the selected companies are really successful (mean score for $\mathrm{p} 4=4.02$ ). It may be noted that the overall performance of the PR function has a slightly lower mean $(\mathrm{p} 3=3.78)$. This indicates that the PR function generally has no power or ability to impact on the success of the company in which it works. However, the most realistic situation seems to be that the PR function is not given enough importance in companies, and therefore has a lower degree of success than the company as a whole. This has been confirmed in some studies in the field of public relations in companies in Serbia (Nikolic et al., 2007; Nikolic et al., 2011). Furthermore, it can be seen that the average score performance evaluation of PR activities ( $22=3.26)$ continues to fall when compared to the overall success of the PR function. Similar to the previous analysis, this is a sign that the evaluation of PR activity is less significant than the overall PR function, i.e., the evaluation is not given the same importance as other PR activities. It should be noted that the mean value for the question about the extent of evaluating PR activity $(\mathrm{p} 1=3.56)$ is higher than the average score for the performance evaluation of PR activities (question $\mathrm{p} 2$ ). This suggests that sometimes evaluation does not provide good enough results: the evaluation of PR activity is carried out, but the performance evaluation and its benefits are not on the level of the investment of time and money. It should be emphasized that these differences are 
not significant. Based on these results and analysis, we can reject assumption A1, at least when it comes to successful companies in Serbia. In these companies, the evaluation of PR activity is not high, but it cannot be said to be significantly neglected.

When it comes to specific PR activities, evaluation is usually done for crisis situations, the organization of special events, corporate image and internal public relations. This is logical given that in these activities it is relatively easy to monitor the quantitative and qualitative effects. On the other hand, the least evaluated public relations activities are for the international market and lobbying. The reason is that these activities are poorly implemented in companies in Serbia. It is widely known that the presence of domestic companies on the international market is very low. When it comes to lobbying, the potential problem lies in the fact that this activity is not regulated by the law as is the case in many countries. According to Vercic and Tkalac Vercic (2012), many countries in the world recognize the growing importance and influence of lobbying. These countries make laws that legally regulate lobbying. Giving lobbying a legislative framework helps to establish certain rules, limits and modes of action for lobbyists and the organizations that hire them.

From the methods for the evaluation of PR activities, the most commonly used is that for measuring quantity. A similar result is proven in research (Watson \& Simmons, 2004). This level uses the simplest techniques and that is why these methods are commonly used in companies in Serbia. Assumption A2 was thus confirmed. It should be noted that the third, highest level method (the method for measuring the effects), has an average representation, and this should not be regarded as a bad result. The fact that in the European Union the most advanced technique of measurement and evaluation in public relations is also used to a lesser degree should also be mentioned (Baskin et al., 2010). The situation is similar in Australia: despite recognizing the importance of evaluation in public relations, PR practitioners are still largely focused on measuring outputs, not outcomes (Xavier et al., 2005). Measurement at the third level still seems to pose a challenge for PR professionals in most countries.

The effects of some PR activities (question p7) have decreased from the first to the third level of evaluation. This is logical given the complexity of PR activities that lead to a change in audit consciousness (second level) and audience behavior (third level). In addition, as shown in question p6, the evaluation is mostly carried out at the first level, so these effects can be observed more easily.

The respondents gave high marks to the significance of the evaluation of PR activities (question p8) both for the success of the current PR activities (those activities for which evaluation is done), and for the future success of PR activities, as well as the overall success of the PR function. On the other hand, the utilization of the evaluation results (question p9) for improving the current PR activities, improving the future of PR activities and improving the function of PR in general, is not at the level of importance that the respondents assigned to the evaluation of PR activities. Clearly there is a dissonance between what is required (desired) and what it is being implemented in practice. PR practitioners in Serbia and their leaders should strive to fill the gap that exists in this area. As mentioned in the theoretical section, this is a situation which often occurs in research studies into the significance of evaluation and its application.

Based on the mean values [0][0] of the p10 group of questions, it can be seen that the biggest obstacle to the evaluation of PR activities is the lack of money and time. Lack of knowledge in the field of the evaluation of PR activities and lack of awareness about the importance of their evaluation do not present such an obstacle. This confirmed assumption A3. 
Awareness of the importance of evaluating PR activity was confirmed by the high marks within the $\mathrm{p} 8$ group. This is certainly a good result and serves as a good starting point for the development of the evaluation of PR activities, and overall PR function in Serbian companies. When it comes to the development of public relations in Serbia, the reference (Nikolic et al., 2012) confirmed some progress in the period between 2006 and 2012.

Question $\mathrm{p} 11$ has the lowest average value in this study. It is clear that few companies in Serbia use the services of external PR agencies in the evaluation of PR activities. This situation is probably the result of confidence in their own PR practitioners, but also the desire to reduce costs. Savings in public relations, indirectly points to the (still) insufficient importance given to the PR function in Serbian companies.

The correlation analysis presented in Table 2, aims to examine the relationship between the degree of implementation of the evaluation of PR activities, the performance evaluation of PR activities, the overall success of the PR function, the success of the company as a whole, the degree of application of different methods for the evaluation of PR activities and various barriers to the evaluation of PR activities. In general, the correlation analysis showed the expected strong connections. However, there are a number of statistically significant correlations, which are discussed below. The analysis was performed according to the characteristic units.

The analysis of the correlation between the first four questions indicates two statistically significant correlations. In this section, the strongest correlation is between the frequency of evaluating PR activity (p1) and the overall success of the PR functions (p3). Hence, intense and continuous evaluation of the performance of PR activities increases the likelihood of the PR function being successful. Also, there is a statistically significant correlation between the success of the PR function (p3) and the overall success of the company (p4). The positive impact of the PR function on a variety of indicators of company performance has been confirmed by previous studies (see, for example, Lee \& Yoon, 2010; Podnar, Lah, \& Golob, 2009; Plowman, 2005).

It is interesting that there is no statistically significant correlation between the extent of evaluating PR activity (p1) and the performance evaluation of PR activities (p2). Obviously, the scope and frequency of performing the evaluation does not necessarily imply quality and effectiveness of evaluation. In addition, it should be noted that there is no statistically significant correlation between the effectiveness of the evaluation of PR activities (p2) and the success of the PR functions (p3). Therefore, the effectiveness of the evaluation of PR activity is no guarantee that the overall PR function will be successful in companies. The question is how, in such circumstances, the strongest correlation is between the extent of evaluating the PR activity (p1) and the overall success of the PR function (p3)? A possible explanation is that frequent evaluation of PR activity indicates the importance given to evaluation, and the overall PR function. The motivation of PR practitioners, as well as an awareness that they will carry out the evaluation of PR activities, lead to stimulated PR practitioners who continuously carry out their work at a high level. So, motivation is very important for PR practitioners, particularly at a time when the PR profession is not particularly appreciated, as is the case in companies in Serbia (Nikoliæ et al., 2007).

Based on the above analysis, it can be concluded that assumption A4 is partially confirmed. It is confirmed in the part related to the influence of the frequency of the evaluation of PR activities on the overall success of the PR function and rejected in the part related to the performance evaluation of the impact of PR activities on the overall success of the PR function. Assumption A5 is rejected, since the frequency of the effectiveness of PR activities 
evaluation, as well as the performance evaluation of PR activities, both have an impact on the overall success of a company. This effect is only indirect with respect to the way the overall success of the PR function affects the overall performance of the company.

The scope of the application of different methods for the evaluation of PR activities (the questions in group p6) has a statistically significant correlation with the frequency of performing evaluations of PR activities (p1) and the degree of success of PR functions (p3). The connection with question $\mathrm{p} 1$ is logical since this issue is also related to the frequency of the implementation of the evaluation of PR activities. Further, the link between the questions from group $\mathrm{p} 6$ with those from $\mathrm{p} 3$ stems from the connection between questions $\mathrm{p} 1$ and $\mathrm{p} 3$, as previously explained. From the group of $\mathrm{p} 6$ questions, the strongest correlation is for question p6.1, which refers to the use of the method for measuring quantity. This was expected and is in line with the results of the descriptive statistics (Table 1).

As was expected, the barriers to evaluating PR activities (the questions from group p10) negatively affect all other issues covered by the correlation analysis. For greater clarity, the first to be analyzed is the impact of the questions from group p10 on the first four questions. Lack of time for the evaluation of PR activities (p10.1) has a statistically significant (negative) impact on the frequency of performing evaluations of PR activities (p1) and the degree of success of PR functions (p3). Furthermore, the lack of money for the performance evaluation of PR activities (p10.2) statistically significantly (negatively) affects the degree of success of the PR function (p3) and the overall success of the company (p4). At the same time, the lack of knowledge for the performance evaluation of PR activities (p10.3) and lack of awareness about the importance of evaluating them (p10.4) do not have a statistically significant correlation with the first four questions. This result is consistent with the results of the descriptive statistics (Table 1). Therefore, the main problems in the evaluation of PR activities are lack of time and money. The problem of lack of time is also related to money: the recruitment of a number of PR practitioners would mean that the work could be allocated to more people thus creating greater space for evaluation. However, the problem is that the top managers in companies in Serbia see hiring new people only as a cost, without a cost - benefit analysis.

In this section it should be further noted that the strongest negative correlation $(-.444 * *)$ exists between the lack of money for the evaluation of PR activities (p10.2) and the overall success of the company (p4). This suggests that less successful companies (for whom money is a problem) use the evaluation of PR activities poorly. Seen from another perspective, the lack of money for evaluating PR activities may indicate the unsuccessful PR function of the observed company, as well as an unsuccessful company as a whole.

Finally, the effect of the questions from group p10 on those issues related to the scope of the application of different methods for the evaluation of PR activities (the questions from group p6), is also negative. In this section, almost all correlations are strong (and negative). The observed barriers to evaluating PR activities negatively affect all levels of measurement and evaluation in public relations. The exception is the obstacle that relates to the lack of awareness of the importance of evaluating PR activities, where this effect is significantly lower. There is no doubt that PR practitioners in Serbia are aware of the importance of evaluating PR activities. However, at this point of the analysis the problem of lack of knowledge in this field arises. This may be due to the fact we are not dealing with a general question of knowledge here, but more specific matters, which are related to a precisely defined area. On 
this basis, the conclusion is that we should be very careful with the assessment of knowledge of PR practitioners in Serbia when it comes to evaluating PR activities.

\section{Conclusion}

PR functions in companies in Serbia are often not given enough importance. Furthermore, the evaluation of PR activities is slightly neglected in comparison to other PR activities. This is not good because the motivation of PR practitioners largely stems from the importance attached to their profession and their work. This motivation generates the quality of the evaluation of PR activities, but also that of the PR function in general.

The frequency of evaluating PR activities does not provide any guarantees that this evaluation will be successful and will have positive effects. Likewise, an effective PR activity evaluation does not ensure that the overall PR function in companies will be successful. However, intensive and continuous evaluation of the effectiveness of PR activities increases the likelihood of the PR function of the company being successful. An effective PR function usually identifies a successful company as a whole. Similarly, companies that are less successful use the evaluation of PR activities poorly.

For the evaluation of PR activities in companies in Serbia the most frequently used method for measuring is quantity. Methods from the second and third stages of measurement and evaluation in public relations are poorly implemented, but are still applied to a higher extent than expected. That is good, but does not mean that companies should stop there. The potential is there and they should definitely continue the development and application of methods of second and third degree of evaluation of PR activities.

The main problems in the evaluation of PR activities are lack of time and money. Awareness of the importance of evaluating PR activities is present in this part and there is definitely no problem with this. However, the results pertaining to knowledge in the field of the evaluation of PR activities are uncertain and somewhat contradictory. PR practitioners seem to think that they know this area, but when it comes to actual situations, they have some doubts about such knowledge.

The gap between what is required (desired) when evaluating PR activities and what is implemented in practice might be filled by joint planning and action on the part of PR practitioners and their managers. This primarily involves assigning adequate and well-deserved importance to the PR function, and evaluation of PR activities. Therefore, managers will be prepared to allocate more time and money to this area. In this way PR practitioners will gain greater motivation, higher job satisfaction, incentives to acquire new knowledge and better performance at work.

The limitation of this study lies in the fact that the survey covers successful companies in Serbia. The state of PR functions and the evaluation of PR activities in average or less successful companies can only be worse. In addition, it should be noted that the assumptions A4 and A5, cannot be fully tested only through such research. For comprehensive testing of these assumptions it is necessary to conduct further qualitative analysis in practical terms. Nevertheless, the results provide a clear picture of the situation in this area and point to the existence of certain relationships between the observed values. 


\section{References}

AMEC - The International Association for Measurement and Evaluation of Communication (2011). Lisbon Measurement Agenda 2020, Accessed 20.11.13. http://amecorg.com/

Baskin, O., Hahn, J., Seaman, S., \& Reines, D. (2010). Perceived effectiveness and implementation of public relations measurement and evaluation tools among European providers and consumers of PR services. Public Relations Review, 36(2), 105-111.

Cutlip, S. M., Center, A. H., \& Broom, G. M. (1985). Effective public relations (6th ed.) Englewood Cliffs, New Jersey: Prentice-Hall.

Cutlip, S. M., Center, A. H., \& Broom, G. M. (2006). Effective Public Relations (9th ed.), Upper Saddle River, New Jersey: Prentice-Hall.

Dozier, D. M. (1990). The innovation of research in public relations practice: Review of a program of studies. Public Relations Research Annual, 2, 3-28.

Fairchild, M. (2002). Evaluation: an opportunity to raise the standing of PR. Journal of Communication Management, 6(4), 305-307.

Gordon, A. E. (2011). Public Relations. Oxford, New York: Oxford University Press.

Grunig, J., (1983). Basic research provides knowladge that makes evaluation possible. Public Relations Quarterly, 28, 28-32.

Grunig, J., \& Hunt, T. (1984). Managing public relations. Orlando, FL: Holt, Reinhart, Winston.

Grupp, R. W. (2010). Research conversations: The Barcelona declaration of research principles. Gainesville, FL: Institute for Public Relations. Accessed 01.12.13. http://www.instituteforpr.org/2010/06/the-barcelonadeclaration-of-research-principles/

IPRA - International Public Relations Association (1994). Public relations evaluation: Profesional accountabolity: Gold Paper Number 11, London.

Kirban, L. (1983). Showing what we do makes a difference. Public Relations Quarterly, 28(3), 22-28.

Kotler, Ph., \& Amstrong, G. (1996), Principles of Marketing, International Editions, Englewood Cliffts, New Jersey: Preteice Hall.

Lee, S., \& Yoon, Y. (2010). Return on investment (ROI) of international public relations: A country-level analysis. Public Relations Review, 36(1), 15-20.

Lindenmann, W. K. (1990). Reseach, evaluation and measurement: A national perspective. Public Relations Review, 16(2), 3-24.

Lindenmann, W. K. (1993). An 'Efectivenes Yardstick' to measure public relations success. PR Quarterly, 38(1), 7-9.

Macnamara, J., (1992). Evaluation: The Achilles Heel of the public relations profession. International Public Relations Review, 15(4), 19.

Macnamara, J., (1993). Public relations and the media: A new influence in agenda-setting and content. Unpublished master's thesis, Deakin University, Geelong, Australia.

Macnamara, J., (1996). Measuring public relations and public affairs. Paper presented to IIR conference, Sydney.

Macnamara, J., (1999). Research in public relations: A review of the use of evaluation and formative research, Asia Pacific Public Relations Journal, 1(2), 107-133.

Macnamara, J. (2005). Jim Macnamara's public relations handbook (5thed.), (Chapter 18, pp. 243-312). Sydney: Archipelago Press.

Nikolic, M., Dorðevic, D., \& Cockalo, D. (2007). Research on certain aspects of PR function in Serbian companies. Journal for East European Management Studies, 12(2), 152-173.

Nikolic, M., Savic, M., Cockalo, D., Spasojevic - Brkic, V., \& Ivin, D. (2011). The impact of Serbian public relations on economic indices, Public Relations Review, 37(3), 332-335.

Nikolic, M., Terek, E., Vukonjanski, J., \& Durin S. (2012). The state of the PR profession in Serbian companies: A comparative study in 2006 and 2012, 19th BledCom International Public Relations Research Symposium, Bled, Slovenia, 6-7 July 2012. 
Noble, P., \& Watson, T. (1999). Applying a unified public relations evaluation model in European context. Paper presented to Translational Communication in Europe: Practice and Research International Congress, Berlin.

Pavlik, J. (1987). Public relations: What research tell us. Newbury Park, CA: Sage.

Plowman, K. D. (2005). Conflict, strategic management, and public relations. Public Relations Review, 31(1), 131-138.

Podnar, K., Lah, M., \& Golob, U. (2009). Economic perspectives on public relations. Public Relations Review, 35(4), 340-345.

PRSA - Public Relations Society of America (2012). Accessed 03.12.13. http://prdefinition.prsa.org/

Radford, G. P., \& Goldstein, S. Z. (2002). The role of research methods in corporate communication. Corporate Communications, 7(4), 252-256.

Sha, B. L. (2011). 2010 Practice Analisys: Pofessional competencies and work categories in Public Relations today. Public Relations Review, 37(3), 187-196.

Vercic, D., \& Tkalac Vercic, A. (2012). Public relations and lobbying: New legislation in Slovenia. Public Relations Review, 38(1), 14-21.

Walker, G. (1997). Public relations prectitioners' use of research, measurement and evaluation. Australian Journal of Communication, 24(2), 97-113.

Watson, T. (1992). Evaluation: Public Relations biggest issue. International Public Relaton Review, 15(3), 31-33

Watson, T. (1997). Measuring the success rate: Evaluating the PR process and PR programmes. In P. J. Kitchen (Ed.), Public relations: Principles and practices (pp. 283-299). Boston: International Thomson Business Press.

Watson, T. (2012). The evolution of public relations measurement and evaluation. Public Relations Review, 38(3), 390-398.

Watson, T., \& Simmons, P. (2004). Public relations evaluation - survey of Australian practitioners. Paper presented at the Australian New Zealand Communication Association Conference, University of Sydney, Australia, July 7-9, 2004.

White, J., \& Blamphin, J. (1994). Priorities for research into public relations practice in United Kingdom, London: City University Business School / Rapier Research.

Wilcox, D. L., \& Cameron, G. T. (2009), Public Relations strategies and tactics (9th ed.). Boston: Prearson Education, Inc., publishing as Allyn \& Bacon.

Xavier, R., Johnston, K., Patel, A., Watson, T., \& Simmons, P. (2005). Using evaluation techniques and performance claims to demonstrate public relations impact: An Australian perspective. Public Relations Review, 31(3), 417-424.

www.pr.org.rs. 